\title{
A COMPARATIVE THERMAL ANALYSIS OF WALLS COMPOSED OF TRADITIONAL AND ALTERNATIVE BUILDING MATERIALS
}

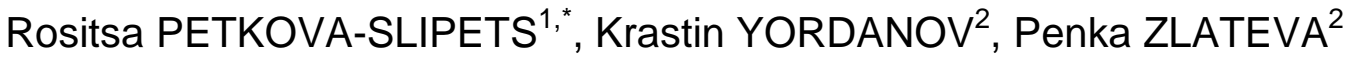 \\ ${ }^{1}$ Department of Civil Engineering, Faculty of Architecture, Varna Free University "Chernorizets \\ Hrabar", Resort Chaika, 9007 Varna, Bulgaria. \\ ${ }^{2}$ Department of Thermal Engineering, Shipbuilding Faculty, Technical University of Varna, Studentska \\ Str.1, 9010 Varna, Bulgaria. \\ corresponding author: rositsa.petkova@vfu.bg.
}

\begin{abstract}
This research aims at comparing the thermal performance of walls made from traditional and alternative building materials. The experimental study involves five types of walls were studied based on perforated ceramic bricks and a mixture of clay, sand with various straw proportions. Specialized software and the finite element method (FEA) were employed for modelling of the thermal processes and their visualization for the different types of walls. A simulation modelling algorithm was developed. The models developed show very good convergence of the results and provide for subsequent design and thermal calculation of constructions made by environmentally friendly materials.
\end{abstract}

\author{
Keywords: \\ Straw; \\ Brick; \\ Finite element modelling; \\ Heat flow; \\ Temperature field.
}

\section{Introduction}

With a view to protecting the environment, along with ensuring comfortable living conditions, the field of sustainable architecture and sustainable building has dramatically developed over the recent years [1 - 4]. The efficient combination of high-tech design, taking into account the location and orientation of objects in space, the use of materials featuring a unique set of properties and modern technologies (renewable energy systems, "smart" control systems, etc.) has enabled construction of buildings of high energy efficiency and a small carbon footprint. Along with efficiency, however, more and more attention is being paid to the environmental friendliness of buildings, especially in terms of materials used. Through the use of ecologically clean and environmentally friendly building materials [5], thermal and hygienic comfort of living is achieved, combined with a better environmental protection and preservation.

Adobe is an example of an ecological material that is traditionally used in many countries around the world due to its universal qualities and behaviour in various climatic conditions (Fig. 1) [6 - 10]. It is a mixture of clay, sand, water and some kind of fibre or organic material (straw, branches, pine needles, sometimes horse or cow manure is added), which are shaped in the form of bricks by means of frames and left to dry outdoors. Adobe buildings are extremely durable and some of the oldest existing buildings in the world are built using this technique. The advantage of adobe bricks is that they can be reused. It is only necessary to "soak" them again in water and put them back in the desired brick shape.

The adobe brick wall can serve as a significant thermal energy reservoir, given the inherent thermal characteristics of solid walls. In tropical and other climatic zones, characterized by hot days and cold nights, the large thermal mass of adobe increases the heat transfer through the wall to the living spaces. Massive walls require a large and relatively long exposure, both to the sun (radiation) and to the surrounding air (convection) before they heat up and begin to transfer heat to the living spaces. 

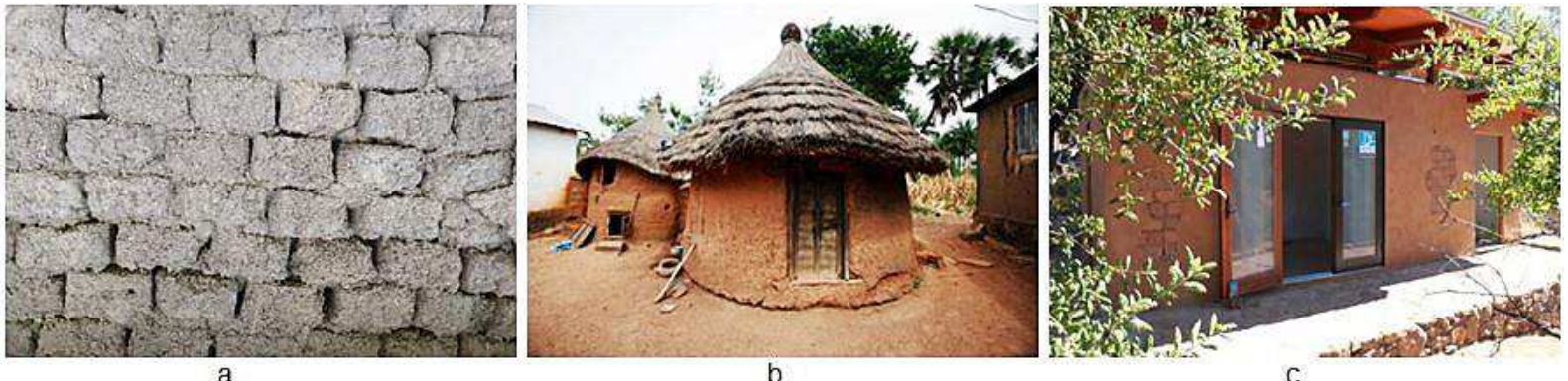

Fig. 1: The use of adobe in construction in different regions of the world: a) adobe brick wall of an agricultural building; b) adobe homes in Togo, West Africa [11]; c) Frelinger Residence, USA [12].

Due to the many possible ratios of the structural components of adobe, information about its thermophysical properties is not available and this raises the need for its study. Taking into account the results of previous studies of the authors [13], the present paper's objective is a comparative analysis of the thermal behaviour of walls of traditional perforated ceramic bricks and different types of alternative materials, a mixture of clay, sand, water and different proportions of straw. Their thermal behaviour was studied by simulation modelling. A new research method widely used to describe and predict the behaviour of different materials and/or constructions [10,14].

\section{Materials and methods}

The present work presents a special algorithm developed by authors for simulation modelling of two types of walls made from different materials in order to conduct a comparative analysis of the thermal behaviour of structures typical of construction practice. 3D simulation models have been created using the software product "Autodesk Inventor Nastran 2020".

\subsection{Experimental materials}

The object of simulation modelling is a wall of traditional perforated ceramic bricks and walls of clay and sand with various proportions of straw added (Fig. 2). The composition of the tested samples, as well as the basic properties of the materials used are presented in Table 1 and Table 2.

Table 1: Samples composition and their properties $[13,15]$.

\begin{tabular}{|c|c|c|c|c|c|c|}
\hline Sample type & \multicolumn{3}{|c|}{ Materials } & $\underset{\mathbf{k g} / \mathbf{m}^{3}}{\rho}$ & $\stackrel{k}{k}$ & $\underset{\mathrm{J} /(\mathrm{kg} \cdot \mathrm{K})}{C_{p}}$ \\
\hline 1 & \multicolumn{3}{|c|}{ Perforated ceramic brick [15] } & 1400 & 0.52 & 1050 \\
\hline 2 & \multirow{4}{*}{ Clay (grey marl) } & \multirow{4}{*}{ Sand } & 0 wt. \% straw & 2000 & 0.498 & 456.78 \\
\hline 3 & & & 0.3 wt. $\%$ straw & 1877 & 0.379 & 721.45 \\
\hline 4 & & & 0.4 wt.\% straw & 1737 & 0.241 & 907.21 \\
\hline 5 & & & 0.5 wt. \% straw & 1683 & 0.219 & 968.83 \\
\hline
\end{tabular}

Table 2: Wall types studied and their construction layers.

\begin{tabular}{|c|c|c|c|}
\hline \multirow{2}{*}{ Wall type } & \multicolumn{3}{|c|}{ Layers } \\
\hline & 1 (outside) & 2 (middle) & 3 (inside) \\
\hline 1 & \multirow{5}{*}{$\begin{array}{c}\text { Render Outside } \\
\text { Lime-Sand Plaster } \\
\left(\delta_{1}=0.025 \mathrm{~m}\right. \\
k=0.87 \mathrm{~W} /(\mathrm{m} \cdot \mathrm{K})[15])\end{array}$} & Perforated ceramic brick & \multirow{5}{*}{$\begin{array}{c}\text { Render Inside } \\
\text { Lime-Sand Plaster } \\
\left(\delta_{3}=0.025 \mathrm{~m}\right. \\
k=0.70 \mathrm{~W} /(\mathrm{m} \cdot \mathrm{K})[15])\end{array}$} \\
\hline 2 & & Type 1 & \\
\hline 3 & & Type 2 & \\
\hline 4 & & Type 3 & \\
\hline 5 & & Type 4 & \\
\hline
\end{tabular}




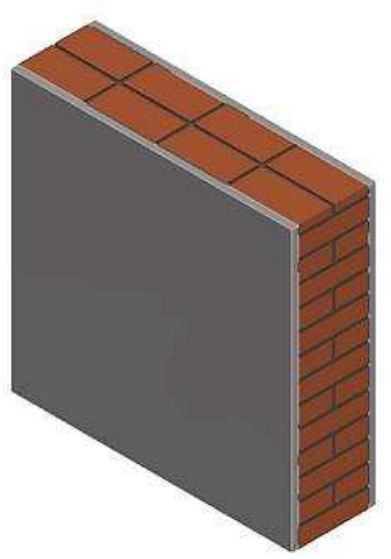

a

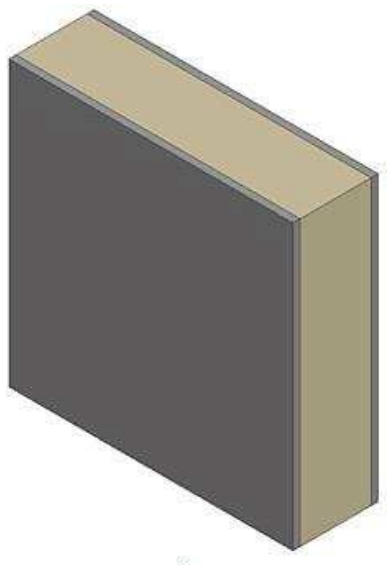

$b$

Fig. 2: Walls types tested (Table 2): a) wall type 1 - Render Outside - Perforated ceramic brick Render Inside; b) wall type 2, 3, 4 and 5 - Render Outside - Clay, sand and various quantity of straw Render Inside.

The samples of clay and sand with a different proportion of added straw are prepared as follows: unbaked clay is dissolved in water to a plastic state and sand is added in a ratio of 1:2. For samples 3, 4 and 5, cutted straw is added in the proportions given in Table 1. The water-clay ratio for all types is 0.5 . The resulting homogeneous mixture is poured into wooden moulds and dried at room temperature for 24 hours. The thermal properties of the clay-sand composites containing straw (Table 1) are defined and indicated in [13].

The perforated ceramic bricks tested are standard, corresponding to BDS EN 771-1:2005. Their thermal properties are the standard ones as set in thermal dimensioning of building structures [15].

\subsection{Simulation modelling}

With the technology of thermal processes, solving problems of this nature requires the application of a special algorithm. For the purposes of the present study, an algorithm was developed and applied. The algorithm is shown in Fig. 3.

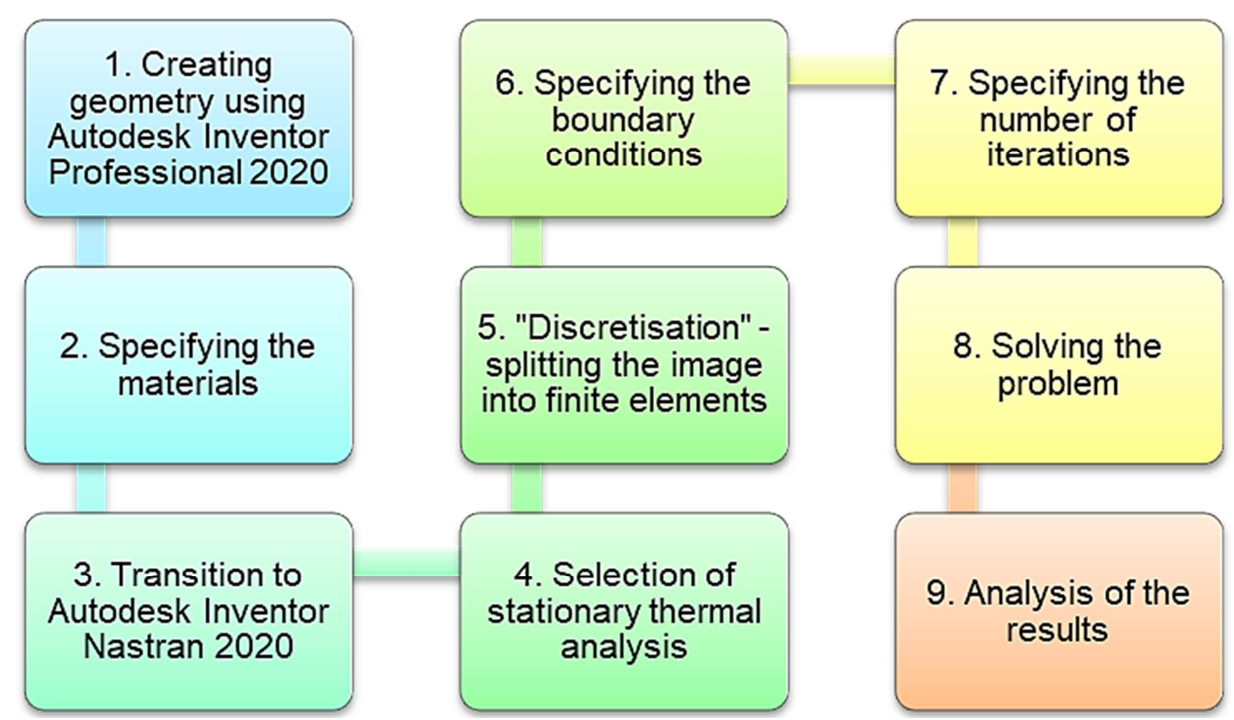

Fig. 3: The algorithm for thermal process calculations using "Autodesk Inventor Professional 2020" and "Autodesk Inventor Nastran 2020".

The geometry of the wall types studied is shown in Fig. 4. The software modelled wall of perforated ceramic bricks and walls of clay and sand with and without straw are illustrated in Fig. 2. 


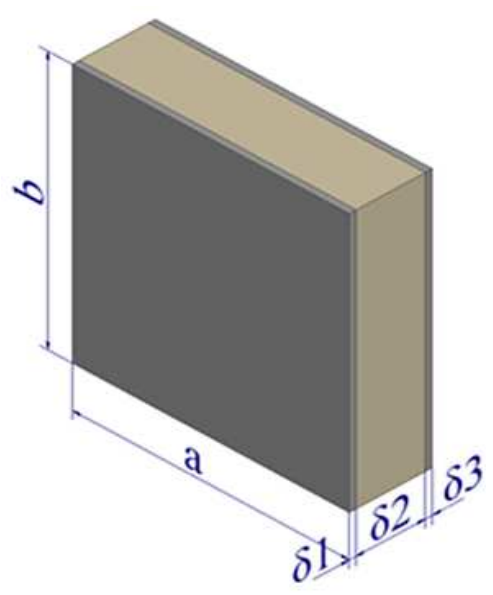

Fig. 4: Geometry of the wall types studied.

The properties of the materials involved in the composition of the modelled walls are presented in Table 1 and Table 3. They are determined by experimental studies and serve as input data for simulation modelling. Materials with the thermophysical parameters of the walls have also been added from the Autodesk Inventor Professional 2020 library.

It was accepted to work with the dimensions of the simulation walls, as follows: $a=1 \mathrm{~m}$ and $b=$ $1 \mathrm{~m}$. The thicknesses of the wall layers are: $\delta_{1}=0.025 \mathrm{~m}, \delta_{2}=0.20 \mathrm{~m}, \delta_{3}=0.025 \mathrm{~m}$ or the total thickness of the wall is $\delta=0.25 \mathrm{~m}$.

The heat transfer coefficient $U$ for each wall type is calculated using the formula [15]:

$$
U=\frac{1}{R_{B i}+\sum_{i=\mathbf{2}}^{n} \frac{\delta_{i}}{k_{i}}+R_{B i}}=\frac{1}{\frac{1}{h_{\theta n i}}+\sum_{i=\mathbf{2}}^{n} \frac{\delta_{i}}{k_{i}}+\frac{1}{h_{\theta ; \theta}}}, \frac{W}{m^{2} \cdot K} .
$$

where: $R_{s i}=0.17\left(\mathrm{~m}^{2} \cdot \mathrm{K}\right) / \mathrm{W}$ - internal surface resistance $[15,16] ; R_{s e}=0.04\left(\mathrm{~m}^{2} \cdot \mathrm{K}\right) / \mathrm{W}$ - external surface resistance, $[4,5] ; \delta_{i}$ - thickness of the $i$-th element, $\mathrm{m} ; k_{i}$ - thermal conductivity coefficient of the $i$-th element, $\mathrm{W} /(\mathrm{m} \cdot \mathrm{K}) ; h_{c ; i}$ - convective coefficient; internal surface, $\mathrm{W} /\left(\mathrm{m}^{2} \cdot \mathrm{K}\right) ; h_{c ; e}$ - convective coefficient; external surface, $\mathrm{W} /\left(\mathrm{m}^{2} \cdot \mathrm{K}\right)$. The calculations' results are shown in Table 3 .

Table 3: Dimensions and thermophysical parameters of the different wall types composition layers.

\begin{tabular}{|c|c|c|c|c|}
\hline \multirow[b]{2}{*}{ Wall type } & \multicolumn{3}{|c|}{ Dimension } & \multirow{2}{*}{$\begin{array}{c}\text { Thermal transmittance } \\
\text { coefficient } \\
U W /\left(\mathrm{m}^{2} \cdot \mathrm{K}\right)\end{array}$} \\
\hline & $\begin{array}{l}a \\
\mathbf{m}\end{array}$ & $\begin{array}{l}b \\
\mathbf{m}\end{array}$ & $\begin{array}{c}\delta \\
\mathrm{m}\end{array}$ & \\
\hline Type 1 & \multirow{5}{*}{1} & \multirow{5}{*}{1} & \multirow{5}{*}{0.25} & 1.32 \\
\hline Type 2 & & & & 1.27 \\
\hline Type 3 & & & & 1.05 \\
\hline Type 4 & & & & 0.75 \\
\hline Type 5 & & & & 0.67 \\
\hline
\end{tabular}

where: $a$ - length, $\mathrm{m} ; b$ - height, $\mathrm{m} ; \delta$ - thickness, $\mathrm{m}$;

The simulation modelling of the thermal processes in the wall types was performed with Autodesk Inventor Nastran 2020 software, which is suitable for the purposes of the present research. A steady-state thermal analysis was used.

For comparison of the results obtained through Autodesk Inventor Nastran 2020, an analytical calculation of the heat flow is carried out according to formula [17]:

$q=U \cdot\left(t_{i}-t_{i}\right) \frac{W}{m^{2}}$, 
where: $U$ - thermal transmittance coefficient $\mathrm{W} /\left(\mathrm{m}^{2} \cdot \mathrm{K}\right), t_{i}$ - internal temperature of air in room, $t_{e}$ external temperature of ambient air.

In Fig. 5 shows the set wall surface boundary conditions, and the values for all wall types examined are: $h_{c ; l}=5.9 \mathrm{~W} /\left(\mathrm{m}^{2} \cdot \mathrm{K}\right) ; t_{i}=22.0{ }^{\circ} \mathrm{C}[15] ; h_{c ; e}=25.0 \mathrm{~W} /\left(\mathrm{m}^{2} \cdot \mathrm{K}\right) ; t_{e}=-9.0{ }^{\circ} \mathrm{C}[15]$ (winter, Varna with $0.4 \%$ error).

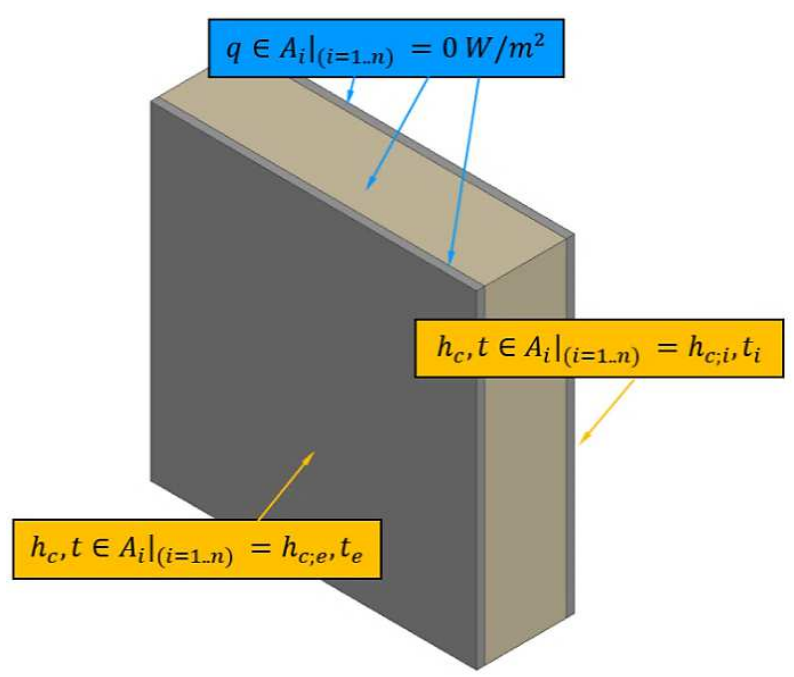

Fig. 5: Set surface boundary conditions of the wall types.

The mathematical modelling of the steady-state thermal analysis is performed by the differential equation (3):

$\frac{\partial}{\partial x}\left[k \frac{\partial T}{\partial x}\right]+\frac{\partial}{\partial y}\left[k \frac{\partial T}{\partial y}\right]+\frac{\partial}{\partial z}\left[k \frac{\partial T}{\partial z}\right]=0$

where: $T$-temperature, $x, y, z$ - axis.

The algorithm developed for 3D modelling of thermal processes in the different wall types allows using the appropriate software to make predictions of the processes, varying the input parameters.

\section{Results and discussion}

The results of the simulation modelling carried out using the algorithm developed are shown in Fig. 6, Fig. 7 and Table 4.

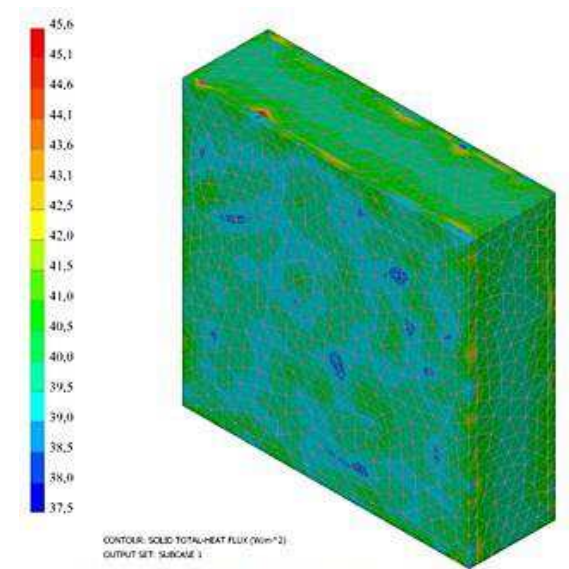

a) Result total heat flow wall type 1

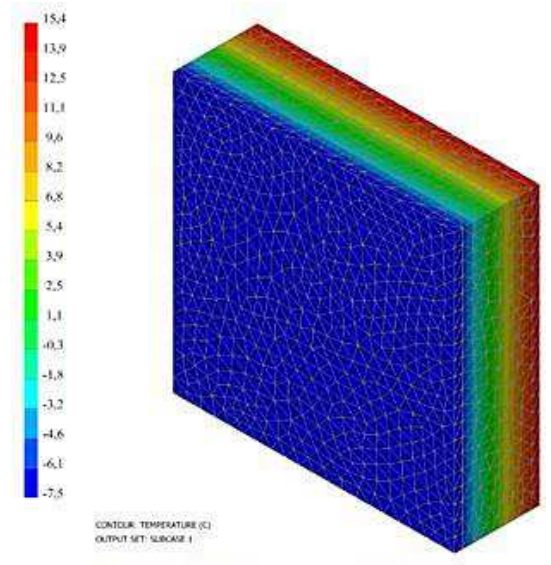

b) Result temperature type 1 


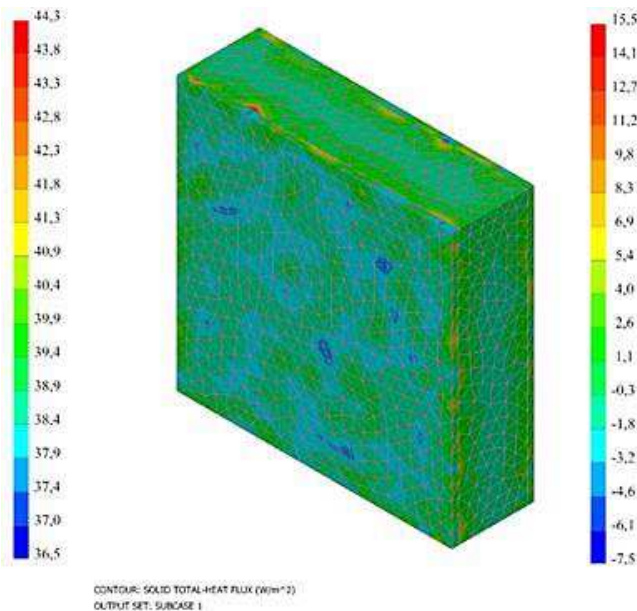

c) Result total heat flow wall type 2

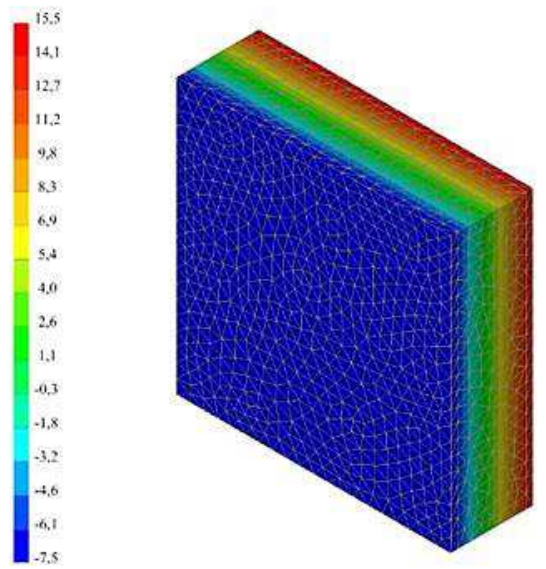

d) Result temperature type 2

Fig. 6: Total heat flow and temperature distribution through: a) and b) - perforated ceramic brick wall thickness; c) and d) - a composite brick from clay and sand.

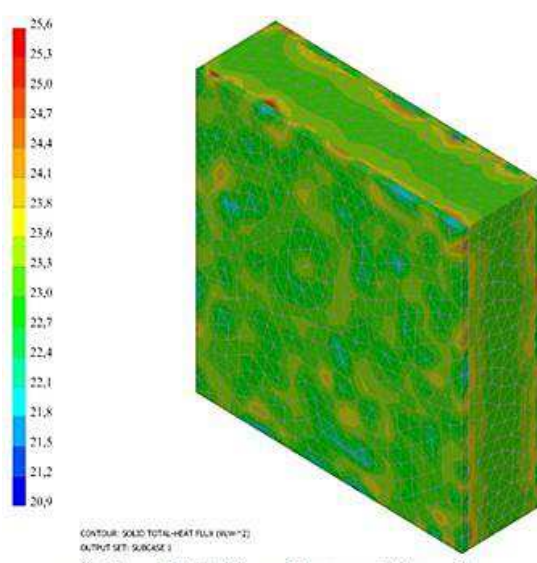

a) Result total heat flow wall type 4

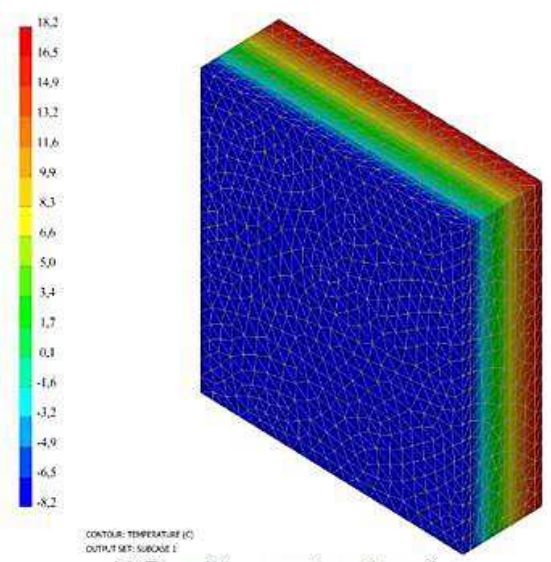

b) Result temperature type 4

Fig. 7: Total heat flow and temperature distribution through wall type 4 thicknes.

Table 4: Wall types analysis results.

\begin{tabular}{|c|c|c|c|c|c|}
\hline \multirow{2}{*}{ Wall type } & \multicolumn{3}{|c|}{ Results (FEA) } & \multirow{2}{*}{$\begin{array}{c}\text { Results Eq.(1) } \\
\mathbf{q}_{\boldsymbol{f}(\mathbf{1})} \mathbf{W} / \mathbf{m}^{2}\end{array}$} & $\begin{array}{c}\text { Error } \\
\%\end{array}$ \\
\cline { 2 - 4 } & $\begin{array}{c}\boldsymbol{t}_{\boldsymbol{s i}} \\
{ }^{\circ} \mathbf{C}\end{array}$ & $\begin{array}{c}\boldsymbol{t}_{\boldsymbol{s e}} \\
{ }^{\circ} \mathbf{C}\end{array}$ & $\begin{array}{c}\boldsymbol{q}_{\text {aver. }} \\
\mathbf{W} / \mathbf{m}^{2}\end{array}$ & 41.0 & 1.34 \\
\hline 1 & 15.4 & -7.5 & 41.6 & 39.3 & 2.80 \\
\hline 2 & 15.5 & -7.5 & 40.4 & 32.7 & 1.83 \\
\hline 3 & 16.6 & -7.8 & 33.3 & 23.1 & 0.87 \\
\hline 5 & 18.2 & -8.2 & 23.3 & 20.9 & 2.87 \\
\hline
\end{tabular}

where: $q_{a v e r}$ - average heat flow from the analysis; $t_{s i}$ - internal surface temperature the wall; $t_{s e}$ - external surface temperature the wall; $q_{t .(1)}$ - heat flow calculated by a formula (1).

The heat flow simulation results for the different wall types indicate that the wall of perforated ceramic bricks has the highest heat transfer $-q_{f(1)}=41.0 \mathrm{~W} / \mathrm{m}^{2}$ and $q_{\text {aver }}=41.6 \mathrm{~W} / \mathrm{m}^{2}$, and the best thermal resistance, and respectively the lowest heat transfer coefficient is determined for the wall of clay, sand and $0.5 \%$ straw additive $-q_{f .(1)}=20.9 \mathrm{~W} / \mathrm{m}^{2}$ and $q_{\text {aver }}=21.5 \mathrm{~W} / \mathrm{m}^{2}$. The percentage errors from the simulation are respectively below $3 \%$.

This indicates that the developed algorithm and mathematical model are correct. The results are reliable and with very good convergence with the experimental data and analytical calculations.

The results obtained provide for the following comparative analysis of the wall types studied. From the point of view of an alternative building material, the mixture of clay, sand and straw surpasses the traditional building material, such as ceramic bricks. As the amount of straw increases, 
so do the insulating properties of the walls. The comparative analysis of the simulation model shows that the software used adequately reproduces the results of experimental studies and determines with sufficiently accurately the total heat flow and temperature distribution in real objects represented by the models of different wall types. This makes it possible to assess the actual behaviour of both the ceramic wall and the clay and sand walls with and without different amounts of straw added.

\section{Conclusions}

The research carried out and the results obtained were used for a comparative thermal analysis of walls made from traditional and alternative building materials and the following conclusions can be drawn:

1. The algorithm developed for calculating heat flows of walls of different materials is adequate and allows its application in specialized software in order to predict the thermal processes, with varying the input parameters.

2. The simulation modelling of the steady-state thermal conductivity in the studied types of perforated ceramic brick walls and walls from a clay and sand matrix with and without straw additives through the mathematical model adequately represents the thermal processes occurring in them and shows good repeatability of the results obtained.

3. In terms of their thermophysical properties, the alternative building material (mixture of clay and sand) has properties similar to those of the traditional building material (perforated ceramic bricks). The values obtained for the heat transfer coefficient of the perforated ceramic brick walls and of the clay and sand walls are $U_{1}=1.32 \mathrm{~W} /\left(\mathrm{m}^{2} \cdot \mathrm{K}\right)$ and $U_{2}=1.27 \mathrm{~W} /\left(\mathrm{m}^{2} \cdot \mathrm{K}\right)$ respectively.

4. The addition of even small amounts of straw to a mixture of clay and sand significantly increases the thermal resistance, and respectively reduces the heat transfer coefficient of Type 3 , Type 4 and Type 5 walls. Depending on the amount of straw added to the matrix of clay and sand, the values of the heat transfer coefficient obtained are $U_{3}=1.05 \mathrm{~W} /\left(\mathrm{m}^{2} \cdot \mathrm{K}\right)$ for the walls with the lowest straw content and $U_{5}=0.67 \mathrm{~W} /\left(\mathrm{m}^{2} \cdot \mathrm{K}\right)$ for those with the highest straw proportion.

The conclusions listed above, as well as the adequacy of the simulation model justify the possibilities for using the alternative building materials studied to improve thermal comfort and increase the energy efficiency of buildings. The application of software products for simulation analysis offers an advanced approach to solving problems of this nature.

\section{References}

[1] MARQUES, B. - LOUREIRO, C. R.: Sustainable Architecture: Practices and Methods to Achieve Sustainability in Construction. IACSIT International Journal of Engineering and Technology, Vol. 5, No. 2, 2013, DOI: 10.7763/IJET.2013.V5.547.

[2] SPOSITO, C. - SCALISI, F.: Sustainable Architecture: the Eco-Efficiency Earth Constructions. European Journal of Sustainable Development, Vol. 6, Iss. 4, 2017, pp. 246-254, DOI: 10.14207/ejst.2017.v6n4p246.

[3] RAGHEBA, A. - EL-SHIMYB, H. - RAGHEBB, G.: Green Architecture: A Concept of Sustainability. Procedia - Social and Behavioral Sciences, Vol. 216, 2016, DOI: 10.1016/j.sbspro.2015.12.075.

[4] LI, W.: Sustainable design for low carbon architecture. Procedia Environmental Sciences, Vol. 5, 2011, pp. 173-177, DOI: 10.1016/j.proenv.2011.03.064.

[5] GOLANSKI, M.: Thermal Renovation of Buildings with the Use of Straw - European Experience. CEER, Vol. 23, Iss. 4, 2016, pp. 61-68, DOI: 10.1515/ceer-2016-0051.

[6] COSTI DE CASTRILLO, M. - PHILOKYPROU, M. - IOANNOU, I.: Comparison of adobes from prehistory to-date. Journal of Archaeological Science: Reports, Vol. 12, 2017, pp. 437-448, DOI: 10.1016/j.jasrep.2017.02.009.

[7] JIMOH, A. O. - DEMENONGU-DEMSHAKWA, J.: The Relationship between Surface Temperature of Building Envelope and Ambient Indoor Temperature for Adobe Brick Building: A Case Study of an Adobe Brick Building in Jos - Nigeria. Journal of Environment and Earth Science, Vol. 10, No. 2, 2020, pp. 115-122, DOI: 10.7176/JEES/10-2-12.

[8] OLUKOYA OBAFEMIA, A. P. - KURTB, S.: Environmental Impacts of Adobe as a Building Material: The North Cyprus Traditional Building Case. Case Studies in Construction Materials, Vol. 4, 2016, pp. 32-41, DOI: 10.1016/j.cscm.2015.12.001.

[9] CALATANA, G. - HEGYIA, A. - DICOA, C. - SZILAGYI, H.: Opportunities Regarding the Use of Adobe-bricks within Contemporary Architecture. Procedia Manufacturing, Vol. 46, 2020, pp. 150157, DOI: 10.1016/j.promfg.2020.03.023. 
[10] ABANTOA, G. - KARKRIB, M. - LEFEBVREB, G. - HORNA, M. - SOLISA, J. - GÓMEZA, M.: Thermal properties of adobe employed in Peruvian rural areas: Experimental results and numerical simulation of a traditional bio-composite material. Case Studies in Construction Materials, Vol. 6, 2017, pp. 177-191, DOI: 10.1016/j.cscm.2017.02.001.

[11]BRINSON, L.: How Adobe Constructions Work. <https://home.howstuffworks.com/homeimprovement/construction/materials/adobe-construction.htm> (3 September 2020).

[12] HUBBELL \& HUBBELL ARCHITECTS: Adobe. <https://www.hubbellandhubbell.com/portfolioitems/burnt-adobe/> (3 September 2020).

[13]PETKOVA-SLIPETS, R. - ZLATEVA, P.: Thermal insulating properties of straw-filled environmentally friendly building materials, Civil and Environmental Engineering, Vol. 13, Iss. 1, 2017, pp. 52-57, DOI: 10.1515/cee-2017-0006.

[14]KOLEV, Z. - KADIROVA, S.: CFD simulation of forced heat transfer of gas in pipe, E3S Web of Conferences, Vol. 112, 2019, 01008.

[15] REGULATION №7 from 2004 г. for Energy Efficiency of Buildings (last update on $21^{\text {st }}$ November 2017 (in Bulgarian).

[16] ISO 6946:2017 - Building components and building elements - Thermal resistance and thermal transmittance - Calculation methods.

[17] MORAN, M. J. - SHAPIRO, H. N. - MUNSON, B. R. - DEWITT, D. P.: Introduction to thermal systems engineering: thermodynamics, fluid mechanics, and heat transfer. John Wilely and Sons, 2003. 